\title{
The burden of avoidable disease from air pollution: implications for prevention
}

\author{
Jonathan Samet, Meghan Buran \\ Colorado School of Public Health, Aurora, United States
}

\begin{abstract}
This paper addresses policy-making related to air quality management in Eastern Europe and Poland, specifically. It reviews the data on air quality for Poland and the region, current regulations governing air quality, and the most recent estimates of the disease burden attributable to air pollution. It considers the public health gains that could be made with more stringent air pollution control measures, contrasting these gains with those that could be achieved with tobacco control.
\end{abstract}

KEY WORDS: air pollution, air quality, policy, burden of disease, Poland.

ADDRESS FOR CORRESPONDENCE: Jonathan Samet, Colorado School of Public Health, 13001 E. $17^{\text {th }}$ Place, MS B119, 80045 Aurora, United States, e-mail: jon.samet@ucdenver.edu

\section{INTRODUCTION}

This paper, building from a presentation at the June, 2019 Calisia World Conference on Family Health, addresses policy-making related to air quality management, focusing on Eastern Europe and Poland specifically. It reviews the data on air quality $\left(\mathrm{PM}_{2.5} / \mathrm{NO}_{2}\right)$ for Poland and the region, current regulations governing air quality, and the most recent estimates of the disease burden attributable to air pollution. It considers the public health gains that could be made with more stringent control measures. The paper contrasts the gains that could be made from air pollution control with those that could be achieved with tobacco control. An earlier paper from the Calisia World Conference addressed the environment and health inequalities, focusing on disparities in exposures and associated health effects [1].

As we look at air pollution as a $21^{\text {st }}$ century problem, we note that air pollution has long been known to harm public health. Historically, its adverse consequences were manifest across the $20^{\text {th }}$ century in well-documented high-pollution episodes that resulted in easily counted excess deaths. The most dramatic such episode was the London Fog of 1952 during which particulate matter pollution was probably 100 -fold above today's
World Health Organization (WHO) guidelines [2]. Excess mortality across the week of the fog was at least 10,000 deaths, primarily among infants and the elderly. Today, many cities in low- and middle-income countries continue to experience levels high enough to affect public health, even reaching concentrations raising concern for surges in the numbers of death and acute morbid events. The frequent occurrence of such high levels in the mega-cities of China and India has gained the attention of the public and policy-makers, leading to plans for addressing air pollution. Air pollution persists as a problem in high-income countries, including some of the dense urban areas of Europe, and parts of the United States, e.g., Southern California - the birthplace of smog.

Over the last decade, air pollution has emerged as a recognized global health threat, largely because of notably large estimates of the disease burden caused by ambient or outdoor air pollution as well as the continued and frequent occurrence of episodes of dramatically high air pollution levels throughout the world [3]. The estimates of burden place air pollution among the leading causes of disease burden in the world, particularly if the burden from household air pollution is counted along with that from ambient air pollution. The scope of the 

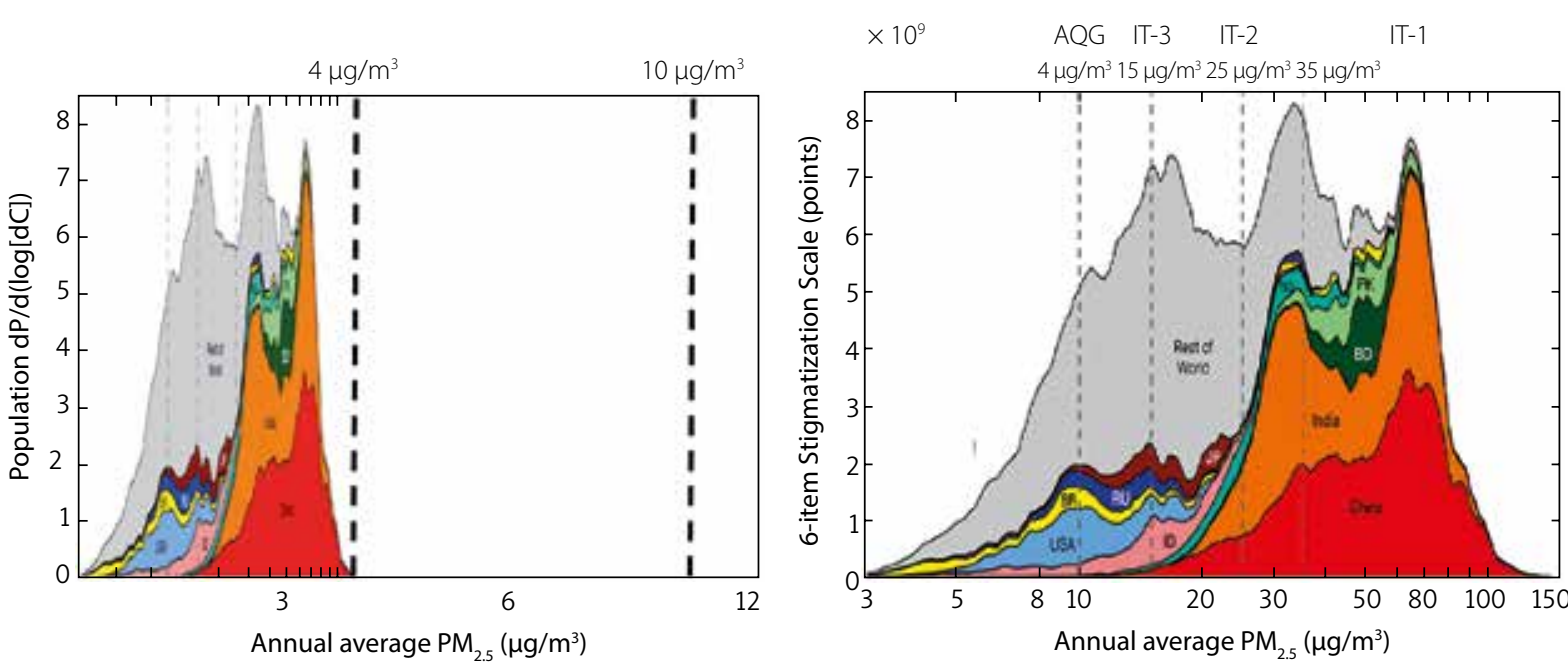

FIG. 1. Estimated Distribution of Global Exposure to $\mathrm{PM}_{2.5}$ and Distribution under Counterfactual Assumption. A) Global and regional distributions of population as a function of annual (2013) average ambient PM $_{2.5}$ concentration for the world's 10 most populous countries. Plotted data reflect local smoothing of bin-width normalized distributions computed over 400 logarithmically spaced bins; equal-sized plotted areas would reflect equal populations. Dashed vertical lines indicate World Health Organization Interim Targets (IT) and the Air Quality Guideline (AQG). Source: [9]. B) The attributable burden represents the maximum benefit that would be achieved if the counterfactual could be met. Adapted from [6]

air pollution burden and its geographical reach led to its being characterized by Tedros Adhanom Ghebreyesus, the WHO's Director General, as the "new tobacco" [4].

These more recent global burden estimates are grounded in ever-more sophisticated methodology for estimating burden: global models for estimation of the concentrations to which people are exposed and refined, epidemiologically-based approaches for characterizing the concentration-response relationships for an increasing number of adverse health outcomes. The concentration-response relationships are derived from analyses of pooled data from epidemiological studies [3]; the concentration estimates come from models that draw on multiple types of data including actual monitoring, land use and other location characteristics, and satellite data [5]. The burden estimates are calculated by applying the concentration-response relationships to the concentration distribution as estimated, making comparison to a "counterfactual" distribution of exposure concentrations that might be achieved via reduction measures. Turning to the well-known example of cigarette smoking, the historical starting point for burden estimation, the implicit counterfactual is a smoking prevalence of zero, that is, there are no smokers. The disease burden reflects the additional morbidity and premature mortality occurring because exposure is greater than the counterfactual value.

For air pollution, the counterfactual used represents the lower end of the distribution of exposure concentrations in the epidemiological studies of air pollution and mortality. The counterfactual value used by the Global Burden of Disease is well below typical values in urban areas. Figure 1 illustrates the concept of the counterfactual based on the estimated global distribution, which shows that much of the population is exposed to $\mathrm{PM}_{25}$ at concentrations above the WHO's annual guideline value of $10 \mu \mathrm{g} / \mathrm{m}^{3}$. The assumed counterfactual shifts the population to the left and exposure is truncated at a value of approximately $4 \mu \mathrm{g} / \mathrm{m}^{3}$. The enormous shift needed to meet the counterfactual range is evident, and for much of the population the counterfactual value is unachievable. Figure 1 highlights the distinction between attributable, i.e., all exposures are below the counterfactual value, and achievable, i.e., the extent to which exposures can be shifted to the left. This distinction needs be communicated in presenting disease burden estimates in policy contexts; the attributable burden represents the maximum benefit that would be achieved if the counterfactual could be met.

There is one further consideration related to using burden estimates in policy decisions: estimates of burden from different agents need to be compared with caution, given the differing bases on which counterfactual values are selected and the consequent differences in the achievable reductions in burden for different agents. The counterfactual value for $\mathrm{PM}_{2.5}$ is derived from the distributions of exposures in epidemiological studies of particulate matter exposure and mortality, leading to a value well below the current WHO guideline. The value represents a target - a theoretically achievable target but recognizing that ambient air pollution cannot be reduced to zero. For smoking, the counterfactual is reaching a prevalence of zero, the long-term target for tobacco control. Comparisons of attributable burdens between particulate matter and tobacco exposures mask differences in what is achievable for each.

With regard to policy, the estimates of burden from air pollution have raised awareness of air pollution not only at the global level, but at national, regional, and local levels. The policy implications of the estimates are evident, as they focus on public health problems that are the 


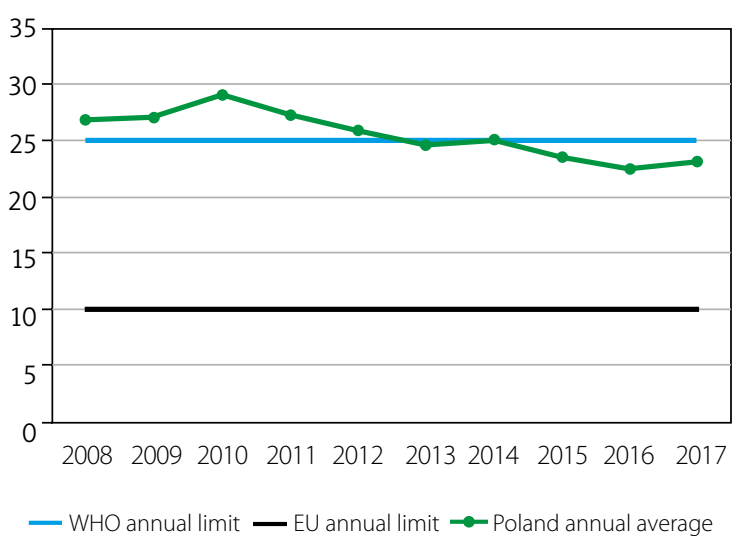

FIG. 2. The trend of $P M_{2.5}$ annual mean concentrations in Poland compared to the EU annual limit value $\left(25 \mu \mathrm{g} / \mathrm{m}^{3}\right)$ and WHO annual limit value $\left(10 \mu \mathrm{g} / \mathrm{m}^{3}\right)$. Source: [8]

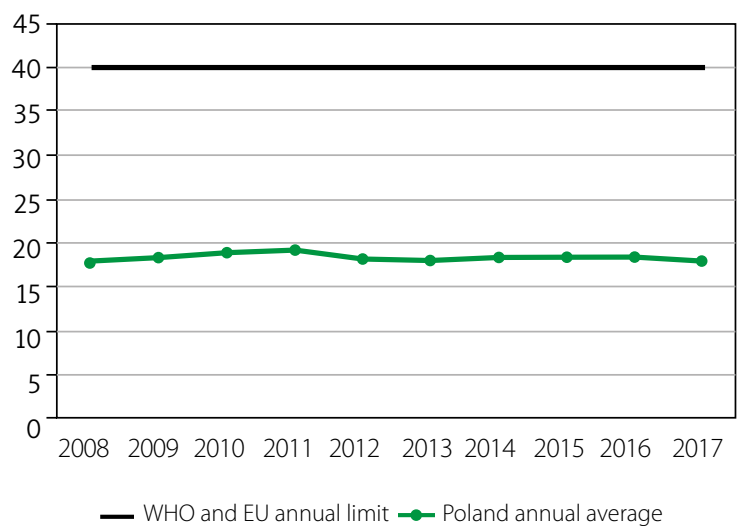

FIG. 3. The trend of $\mathrm{NO}_{2}$ annual mean concentrations in Poland compared to the EU and WHO annual limit values $\left(40 \mu \mathrm{g} / \mathrm{m}^{3}\right)$. Source: [8]

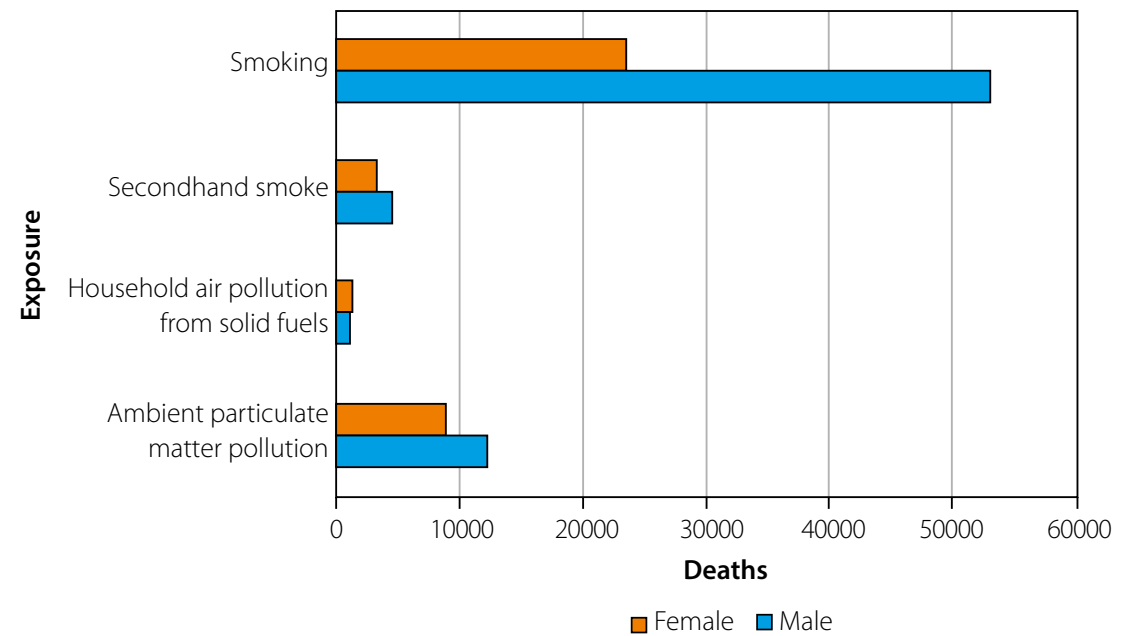

FIG. 4. Deaths attributable to smoking and air pollution, Poland 2017, all causes, both genders, all ages. Source: [8]

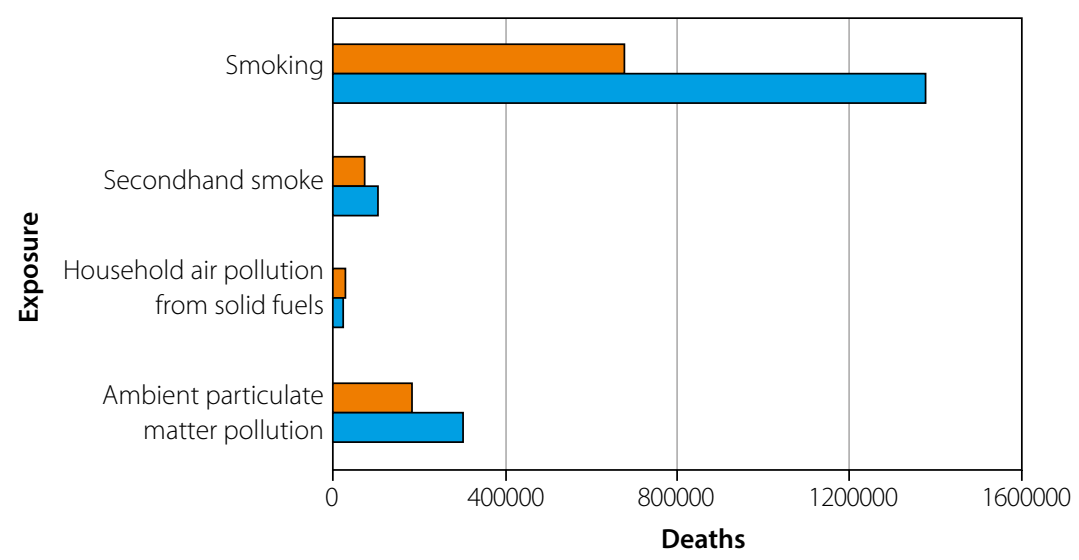

口Female $\square$ Male

FIG. 5. DALYs attributable to smoking and air pollution, Poland 2017, all causes, both genders, all ages. Source: [8] 
purview of national and local public health authorities. The comparison of the magnitude of the air pollution burden from air pollution to that from tobacco is attention-getting, as the dangers of tobacco are well known, but this comparison is potentially misleading because of the distinction between the attributable, reflecting the counterfactual, and the achievable burden, the reduction that can actually be achieved. The comparability of the tobacco and air pollution estimates of burden makes this distinction evident. For 2017 at the global level, the estimates of attributable premature deaths were 2,937,087 for ambient air pollution, 1,640,600 for household air pollution, and 7,099,111 for tobacco smoking [7]. However, the extent to which the burden could be reduced by current interventions differs for air pollution and tobacco smoking.

\section{DISEASE BURDEN ESTIMATES FOR POLAND: AIR POLLUTION AND SMOKING \\ AIR POLLUTION}

We consider the burden due to airborne particulate matter (PM) as indexed by particulate matter less than 2.5 micron in aerodynamic diameter $\left(\mathrm{PM}_{2.5}\right)$ and also from household air pollution, a problem that persists in Poland because of the burning of coal for home heating. Data are also available on levels of nitrogen dioxide $\left(\mathrm{NO}_{2}\right)$, emitted by motor vehicles and industrial sources. In congested metropolitan areas, such as Warsaw, $\mathrm{NO}_{2}$ is considered as a useful indicator of traffic-related air pollution.

Annual average levels of $\mathrm{PM}_{2.5}$ in Poland from 20082017 were around the level of the European Standard of $25 \mu \mathrm{g} / \mathrm{m}^{3}$ and tending down somewhat over these 10 years (Fig. 2). The levels, however, were well above the annual WHO guideline $\left(10 \mu \mathrm{g} / \mathrm{m}^{3}\right)$ and the National Ambient Air Quality Standard (NAAQS) of the US Environmental Protection Agency $\left(12 \mu \mathrm{g} / \mathrm{m}^{3}\right)$. Poland's annual mean average of $\mathrm{NO}_{2}$ was consistently under the European annual limit value of $40 \mu \mathrm{g} / \mathrm{m}^{3}$ from 2008 2017, the most recent year of reported data (Fig. 3) [9]. Poland's annual mean average remained consistently between 15 and $20 \mu \mathrm{g} / \mathrm{m}^{3}$ per year. The highest annual average of $\mathrm{NO}_{2}$ was in 2011 at $19.3 \mu \mathrm{g} / \mathrm{m}^{3}$ and the lowest at $17.8 \mu \mathrm{g} / \mathrm{m}^{3}$ in 2008 , all below the European Union annual limit value.

In 2017 based on the Global Burden of Disease estimates, air pollution contributed to about 23,500 premature Polish deaths (Fig. 4) with most coming from ambient air pollution. Gender differences between deaths by cause are also apparent. Men were more likely to die from illnesses related to ambient particulate matter exposure, reflecting differences between men and women in background rates of the diseases affected by air pollution. Deaths attributed to household air pollution exposure were very similar between genders. Ambient and household air pollution also contributed to disease burden, as indexed by disability-adjusted life-years lost or DALYs (Fig. 5).

\section{SMOKING}

Smoking has long been prevalent in Poland. Fortunately, the rates have dropped over time, but 19.3 percent of women and 26.7 percent of men were smokers in 2015. The most recent estimates for burden of disease from 2017 show that smoking is a leading contributor to disease burden in men and women (Figs. 4 and 5). For deaths, the total of premature deaths is close to 80,000 from active smoking with an additional 8,000 from secondhand smoke and the disease burden, as indexed by DALYs, is far higher than that from air pollution, even with ambient and household air pollution combined.

\section{CONCLUSIONS}

The 2019 Calisia World Conference on Family Health focused on factors that can be addressed to improve population health. Both smoking and ambient air pollution make major contributions to disease burden in Poland, in spite of substantial gains in tobacco control and improvements in air quality over the long-term. Both are externally imposed on populations; air pollution is an external, unacknowledged cost of operating vehicles, polluting industry, and power generation while tobacco smoking is a consequence of a massive, profit-making industry that persists in selling a lethal product. Both can be further controlled with reduction of the burden from non-communicable diseases. And, for both, policy interventions will be opposed by industrial, profit-making sectors.

The burden estimates (Figs. 4 and 5) indicate the magnitude of the gains that could be made, obviously much larger for tobacco smoking than for air pollution. Additionally, tobacco control targets for reduction may be more readily achievable than air pollution goals at present.

We caution, however, against an artificial contest between tobacco control and air quality management. Both are essential and need attention from the policy perspective, and they are the primary responsibility of different sectors in the public health and regulatory sectors. Undoubtedly, air quality control would be more expensive than tobacco control, but the resources used for addressing the two exposures are not interchangeable.

The burden estimates show that gains could be made. Poland has long been a leader in tobacco control in Eastern and Central Europe and the prevalence of smoking should continue to trend downwards, although electronic cigarettes, including those heavily marketed in Poland such as IQOS, are a new concern with regard to youth [10]. Air pollution control has proved challenging, particularly given the extensive reliance on coal, and Poland is not compliant with European Union air quality limits (Fig. 2). Sources still include residential coal burning, 
a contributor to household air pollution and to ambient air pollution, and high-polluting vehicles and industrial sources remain prominent. There are opportunities for gains through regulatory actions, and Poland has implemented its Clean Air Program to modernize homes [11].

In addressing the sweeping public health problems of air pollution and tobacco smoking, broad and intersectoral conversations are needed. The 2019 Calisia World Conference on Family Health provided a platform for such discussion and the meeting's model should be maintained as a vehicle for assuring communications between the public health community and the other sectors involved in making the policy changes needed to protect public health.

\section{DISCLOSURE}

The authors report no conflict of interest.

\section{References}

1. Samet J. The environment and health inequalities: problems and solutions. J Health Inequal 2019; 5 (1): 21-27.

2. World Health Organization. Air Quality Guidelines: Global Update 2005 - Particulate matter, ozone, nitrogen dioxide and sulfur dioxide. World Health Organization, Copenhagen 2006.

3. Cohen AJ, Brauer M, Burnett R, et al. Estimates and 25-year trends of the global burden of disease attributable to ambient air pollution: an analysis of data from the Global Burden of Diseases Study 2015. Lancet 2017; 389 (10082): 1907-1918.

4. The Guardian. Air pollution is the 'new tobacco', warns WHO head. Available from: https://www.theguardian.com/environment/2018/oct/27/air-pollution-is-the-new-tobacco-warnswho-head (accessed: (accessed: 13 December 2019).

5. van Donkelaar A, Martin RV, Spurr RJD, Burnett RT. High-Resolution Satellite-Derived PM2.5 from Optimal Estimation and Geographically Weighted Regression over North America. Environ Sci Technol 2015; 49 (17): 10482-10491.

6. Brauer M, Freedman G, Frostad J, et al. Ambient Air Pollution Exposure Estimation for the Global Burden of Disease 2013. Environ Sci Technol 2016; 50 (1): 79-88.

7. Institute for Health Metrics and Evaluation. Global Burden of Disease (GBD) 2017. Available from: http://www.healthdata. org/gbd (accessed: 13 December 2019).

8. Institute for Health Metrics and Evaluation. GBD Compare Data Visualization. Available from: http://www.healthdata. org/data-visualization/gbd-compare (accessed: 16 December 2019).

9. European Environmental Agency. Poland - Air pollution country fact sheet 2019. Available from: https://www.eea.europa eu/themes/air/country-fact-sheets/2019-country-fact-sheets/ poland (accessed: 13 December 2019).
10. Goniewicz ML, Gawron M, Nadolska J, et al. Rise in Electronic Cigarette Use Among Adolescents in Poland. J Adolesc Health 2014; 55 (5): 713-715.

11. Pinerua C. The Fight for Clean Air in Poland Requires Both Knowledge and Determination. In: Eurasian Perspectives. Vol 2019: World Bank Blogs, 2019. Available from: https://blogs. worldbank.org/europeandcentralasia/fight-clean-air-poland-requires-both-knowledge-and-determination (accessed: 16 December 2019).

\section{AUTHORS' CONTRIBUTIONS}

Both authors wrote the article, critically reviewed the publication and finally approved it. 